Western University

Scholarship@Western

3-1-2019

Cognition and the brain of brood parasitic cowbirds.

David F Sherry

Mélanie F Guigueno

Follow this and additional works at: https://ir.lib.uwo.ca/psychologypub

Part of the Behavioral Neurobiology Commons, Biology Commons, and the Psychology Commons

Citation of this paper:

Sherry, David F and Guigueno, Mélanie F, "Cognition and the brain of brood parasitic cowbirds." (2019).

Psychology Publications. 175.

https://ir.lib.uwo.ca/psychologypub/175 


\title{
Cognition and the brain of brood parasitic cowbirds
}

\author{
David F. SHERRY ${ }^{1}$ and Mélanie F. GUIGUENO ${ }^{2}$ \\ ${ }^{1}$ Department of Psychology, Western University London, Ontario and ${ }^{2}$ Department of Natural Resource Sciences, McGill University, \\ Montreal, Quebec, Canada
}

\begin{abstract}
Cowbirds are brood parasites. Females lay their eggs in the nests of other species, which then incubate the cowbird eggs and raise the young cowbirds. Finding and returning to heterospecific nests presents cowbirds with several cognitive challenges. In some species, such as brown-headed cowbirds (Molothrus ater), females but not males search for and remember the locations of potential host nests. We describe recent research on sex differences in cognition and the hippocampus associated with this sex difference in search for host nests. Female brown-headed cowbirds perform better than males on some, but not all, tests of spatial memory and females show a pattern of adult hippocampal neurogenesis not found in males or in closely related non-parasitic birds. Because of the apparent specialization of the hippocampus, brown-headed cowbirds may be a good model in which to examine spatial information processing in the avian hippocampus and we also describe recent research on the spatial response properties of brown-headed cowbird hippocampal neurons.
\end{abstract}

Key words: adult neurogenesis, brood parasites, cowbirds, hippocampus, sex differences, spatial memory

\section{INTRODUCTION}

Brood parasites avoid the costs of nest building, incubation and parental care by laying their eggs in the nests of other birds. For obligate brood parasites, there is no other path to successful reproduction. It therefore seems reasonable to suppose that natural selection has acted on behavior, cognition and the brain of brood parasites to increase individual reproductive success achieved by

Correspondence: David Sherry, Advanced Facility for Avian Research, Department of Psychology, Western University, London ON N6G 1G9, Canada.

Email: sherry@uwo.ca this brood parasitic way of life. Selection should be no less intense on brood parasites than on non-parasites, and non-parasites possess a vast range of behavioral, cognitive, physiological and neural specializations that promote successful reproduction (Lack 1972; Williams 2012; Deeming \& Reynolds 2016). The present paper describes cognition and the brain of brood parasites, focusing on recent research on sex differences in spatial memory and the hippocampus of cowbirds.

There are 6 major groups of interspecific brood parasites: cowbirds, honeyguides, parasitic finches, Old World cuckoos, New World ground-cuckoos, and 1 species of parasitic duck (Davies 2000). To succeed in having heterospecific parents incubate their eggs and raise their young, brood parasites have to solve a number of problems that non-parasites do not, and many of these 
problems are cognitive:

1. Find potential host nests. Most songbird hosts of cowbirds take a great deal of care to conceal their nests to reduce predation on eggs, nestlings and incubating adults, and to reduce brood parasitism.

2. Remember and revisit potential host nests. Having found a nest, female cowbirds return to it later, either to monitor host clutch completion, to lay one of her own eggs, or to remove a host egg (Sealy 1992; Scardamaglia et al. 2017).

3. Determine the stage of host clutch completion. Female cowbirds prefer to lay in host nests in which a few eggs have been laid but the clutch is not yet complete to ensure that her egg hatches with or before the host's eggs (Sealy 1995).

4. Monitor the host's response to brood parasitism (Hoover \& Robinson 2007) and the reproductive outcome of the cowbird's brood parasitic behavior (Louder et al. 2015).

Some of the cognitive processes involved in brood parasitism have been examined in current research. These include spatial memory, especially sex differences in spatial memory (Astié et al. 1998; Guigueno et al. 2014, 2015; Astié et al. 2015), numerical ability (White et al. 2007, 2009) and specializations in the brain that accompany these cognitive specializations (Sherry et al. 1993; Reboreda et al. 1996; Clayton et al. 1997; Nair-Roberts et al. 2006; Guigueno et al. 2016).

The research we describe examines how the brood parasitic mode of reproduction has modified cognition and the brain of brood parasites. We describe sex differences in spatial memory that have been found in brown-headed cowbirds and sex differences in the brain, specifically in the size of the hippocampus and in adult hippocampal neurogenesis, that are associated with these sex differences in spatial memory. Given the apparent specialization of the brown-headed cowbird hippocampus, we also describe recent research examining the spatial response properties of neurons in the brown-headed cowbird hippocampus.

\section{SEX DIFFERENCES IN SPATIAL MEMORY}

Female brown-headed cowbirds [Molothrus ater (Boddaert, 1783)], parasitize over 200 different species of host and can lay up to 40 eggs in a breeding season (Scott \& Ankney 1980, 1983; Rothstein et al. 1987), compared to mean clutch sizes of 4-5 eggs for temperate zone birds occupying the same geographic range as brown-headed cowbirds (Jetz et al. 2008). Brown-headed cowbirds probably do not achieve a 10 -fold reproductive advantage compared to non-parasites from the large number of eggs they produce (Woolfenden et al. 2003), but their brood parasitic behavior does require finding and returning to a very large number of potential host nests.

Female brown-headed cowbirds search for host nests in which to lay their eggs but males do not. This division of labor between the sexes does not occur in all cowbirds. In the South American screaming cowbird (Molothrus rufoaxillaris Cassin, 1866) males and females search for host nests together. However, in brown-headed cowbirds, search is performed by females alone and it occurs some time before females actually lay their parasitic egg. Females often lay at dawn, or earlier (Neudorf \& Sealy 1994), and so they are not searching at this time for potential host nests. They are going to a nest they have previously discovered. After laying, they may spend the rest of the morning searching for host nests in which to lay eggs on subsequent days (Scott 1991), or re-visiting nests they have already discovered to check on the progress of host egg laying and clutch completion (White et al. 2009). Females find nests by flying into understory vegetation to flush incubating hosts or by watching the nest building behavior of hosts from the canopy or the forest floor (Norman \& Robertson 1975). Females are choosy about the state of the nest in which they lay their egg. They prefer to lay in a nest that already has some eggs in it, but not too many. In fact, female brown-headed cowbirds prefer to lay in a host nest with 3 eggs in it, but it is equally important that it be an active nest to which the host parent is still adding eggs. David White and his colleagues found that day-to-day changes in the number of eggs in a host nest can have a major effect on how likely a female brown-headed cowbird is to place one of her own eggs in that nest (White et al. 2009). This preference for nests with a daily change in egg number occurs because a nest in which the number of eggs is unchanging is a nest in which the host has ceased laying and begun incubation. If incubation has already begun, there is really no way to determine when those eggs are likely to hatch. If they hatch before the cowbird egg has completed development, the cowbird egg will be abandoned and never hatch. In contrast, a nest to which the host is still adding eggs is a nest in which incubation has not yet begun, and a cowbird egg placed in such a nest will hatch along with or even before the host's young.

White et al. (2009) showed that females attend to the number of eggs in a host nest by allowing females to inspect artificial host nests in which the researchers ex- 
perimentally manipulated the number of eggs. In one experiment, brown-headed cowbirds were allowed to observe one nest in which the number of eggs was stable at 3 over successive days. In another nest, brown-headed cowbirds saw the number of eggs increase from 1 to 2 and from 2 to 3 over successive days. When given the opportunity to lay their own eggs, female brown-headed cowbirds preferred to lay in the nest in which the number of eggs increased over successive days. Both nests contained 3 eggs on test days, but brown-headed cowbirds had seen the number of eggs change over days in one nest but not the other. To do this in the wild, a female brown-headed cowbird would have to remember the spatial location of the nest and reliably return to it on successive days.

Because it is females that search for and revisit potential host nests, it is possible that female cowbirds have better spatial memory than males. Sex differences in spatial memory occur in other animals, usually favoring males in species in which males have larger home ranges than females (Gaulin 1992). We tested for a sex difference in spatial memory in brown-headed cowbirds in two ways. In one experiment, brown-headed cowbird males and females searched for food hidden in covered cups in an indoor enclosure. In another experiment, birds performed spatial tests on a touchscreen for food reward.

\section{SPATIAL SEARCH}

We wished to compare spatial memory between male and female brown-headed cowbirds in tasks that

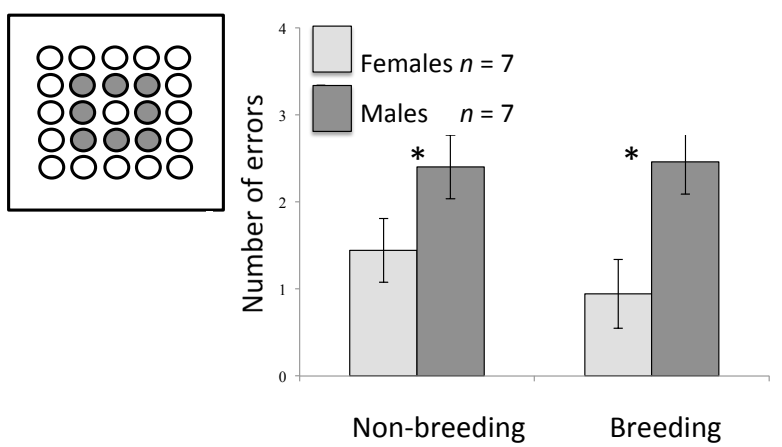

Figure 1 Female brown-headed cowbirds make fewer errors than males in a task that requires remembering for $24 \mathrm{~h}$ which of 8 food cups contained food. There is no effect of breeding condition. Insert in upper left shows the apparatus. Circles represent food cups, of which any of the 8 shown in gray could be randomly baited on a trial. resembled search for host nests, but of course male brown-headed cowbirds do not search for host nests. We therefore used a food rewarded task, but tried to simulate important elements of spatial search for host nests (Guigueno et al. 2014). Males and females searched an array of covered food cups in a $1.8 \times 1.8-\mathrm{m}$ wire mesh enclosure. There were 25 cups arranged in a $5 \times 5$ pattern and any of the 8 interior cups in the array (the center-most cup was excluded) could be baited with food (Fig. 1). Birds searched until they found the one baited cup, ate the food it contained and then returned to their home cage. After a delay of $24 \mathrm{~h}$ they returned to search the array. The same food cup was baited and birds searched again. To minimize possible use of olfactory cues, all cups were shaken for $15 \mathrm{~s}$ with food in them before each trial. On the following day, a new trial commenced in which a new randomly selected cup was baited, birds searched until they found it, and then had to remember that new spatial location for $24 \mathrm{~h}$. These conditions were intended to simulate search for host nests in which females locate potential host nests and then return to them the following day, either to monitor host clutch completion or to lay an egg in the host nest. We tested birds in both breeding and non-breeding condition, induced in the lab by manipulation of photoperiod and verified by hormone assay, frequency of song by males, and egg laying by females.

Females performed better than males at this task, making fewer errors before relocating the baited food cup on tests and taking more direct paths to the correct food cup (Figs 1 and 2). Although our manipulation of photoperiod successfully brought birds into breeding

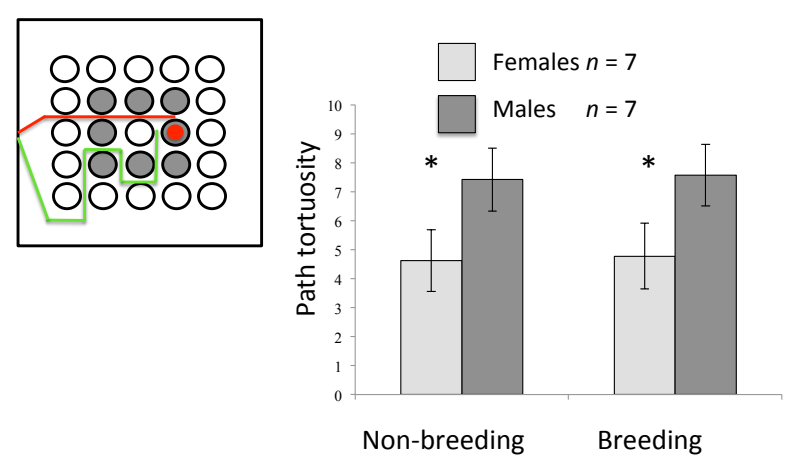

Figure 2 Females take more direct paths to a remembered food cup than males. There is no effect of breeding condition. Path tortuosity equals the ratio of the length of the path taken by the bird (green) to length of the most direct path (red). 
condition as shown by higher androgen levels in males and females, increased song in males and egg laying by some females (Guigueno et al. 2014), there was no effect of breeding condition on performance of the spatial memory task.

Females therefore appear to have better spatial memory than males in a task that resembles, in some ways, search for potential host nests. This sex difference in spatial ability is the reverse of the sex difference sometimes found in mammals, in which males exhibit greater spatial ability than females. The explanation for superior male spatial ability that is often given is that males, depending on breeding system, range more widely in search of mating opportunities than females do (Gaulin 1992; Sherry et al. 1992). In polygynous meadow voles [Microtus pennsylvanicus (Ord, 1815)], males have a larger home range than females, better spatial ability in laboratory tests and a relatively larger hippocampus (Gaulin \& FitzGerald 1986, 1989; Jacobs et al. 1990). These sex differences are not found in monogamous pine [Microtus pinetorum (Le Conte, 1830)] and prairie voles [Microtus ochrogaster (Wagner, 1842)] in which male and female home range size does not differ. Among male meadow voles, spatial ability is correlated with male home range size and, hence, with the number of female meadow voles visited and the number of litters sired (Spritzer et al. 2005). What our results with brown-headed cowbirds show is that sex differences in spatial ability do not depend strictly on sex but instead on sex-specific patterns in the use of space. In mammals in which males compete for mating opportunities by increasing their home range size, natural selection can favor better spatial ability in males than in females. In a species like brown-headed cowbirds, in which females compete for breeding opportunities by searching for host nests, natural selection can favor better spatial ability in females.

\section{SPATIAL SEARCH ON A TOUCHSCREEN}

Does the sex difference in spatial ability that we found in brown-headed cowbirds depend on the kind of spatial task the birds perform? We designed a second task that tested spatial ability but did not resemble search for host nests by female brown-headed cowbirds (Guigueno et al. 2015). In this delayed matching to sample task, birds pecked a sample stimulus on a touchscreen and then after a delay pecked the stimulus, from among a set of 3 stimuli, that matched the sample (Fig. 3). In one version of the task, pecking the stim- ulus that matched the sample in spatial location on the screen produced food reward. In another version of the task, pecking the stimulus that matched the sample in color produced food reward. The delay between pecking the sample and presentation of the test stimuli was varied to produce retention intervals (RIs) of 15, 30, 45 and $60 \mathrm{~s}$. Males and females were tested in both breeding and non-breeding condition induced by manipulation of photoperiod.

Both males and females performed better on the spatial version of this task than on the color version (Fig. 4). There were interesting differences, however, between performance on this touchscreen task and performance on the open field task described previously. On the spatial version of the touchscreen task, males performed better in breeding condition than in non-breeding condition, and males in breeding condition performed better than females in breeding condition (Fig. 5a). Retention intervals affected male and female performance differently. Males performed better than females at the 15-s RI and their performance declined with increasing RI. Female performance was not affected by RI, and there was no interaction between RI and breeding condition.

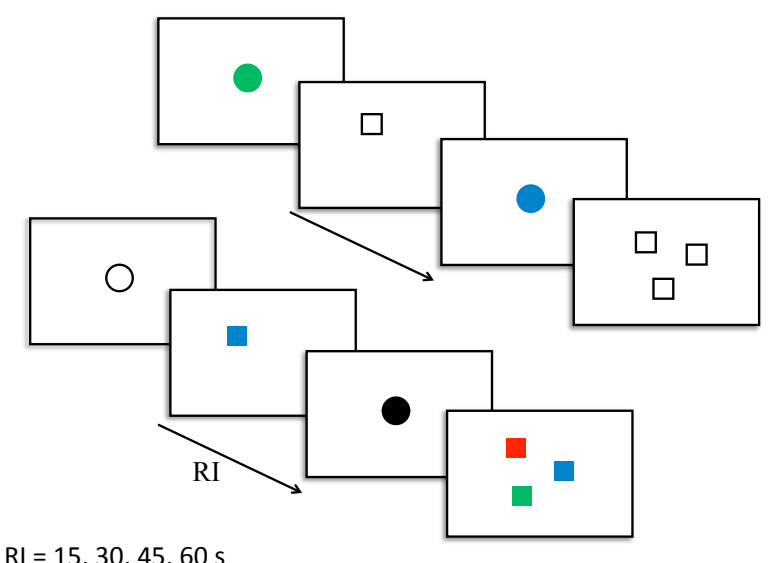

Figure 3 Schematic diagram of space (upper) and color (lower) touchscreen stimuli. Birds first pecked a fixation point (green circle for the spatial task, white circle for the color task) to make a sample stimulus appear on the screen. Pecking the sample stimulus led to retention interval (RI) of $15,30,45$ or $60 \mathrm{~s}$. Birds then pecked a second fixation point (blue circle for the spatial task, black circle for the color task) to make the sample and distractor stimuli appear on the screen. Pecking the correct sample among the distractors produced a food reward; pecking a distractor produced a 5-s lights out period. 
The only notable effect in the color version of the touchscreen task (apart from the fact that birds showed lower accuracy than on the spatial task) was that females performed better in breeding than in non-breeding condition (Fig. 5b).

The results of this touchscreen experiment and the spatial search task described earlier show that sex differences in spatial ability depend on the way in which spatial ability is tested. Indeed, "spatial ability" likely consists of multiple abilities that differ in the kind of stimuli that are processed and the behaviors they influence. The open field task (Guigueno et al. 2014) more closely resembles search for potential host nests than the touchscreen task (Guigueno et al. 2015). It required animals to search for one location among many, and, having found it, to remember that location for $24 \mathrm{~h}$. In the following trial, birds had to search for a new baited location that would be rewarded $24 \mathrm{~h}$ later. The task required locomotion and navigation in a $1.8 \times 1.8$-m space and females performed better on this task than males in both the directness of their path to the correct location and the number of errors they made before getting there. On the touchscreen task, birds were shown a stimulus on a vertical surface a few centimeters in front of them, had to remember this stimulus for up to $60 \mathrm{~s}$, and then identify it again embedded among distractor stimuli. No locomotion or navigation were involved. Instead, birds had to remember a location (or a color) presented in their near visual field. Breeding males performed best at this task, better than breeding females and better than

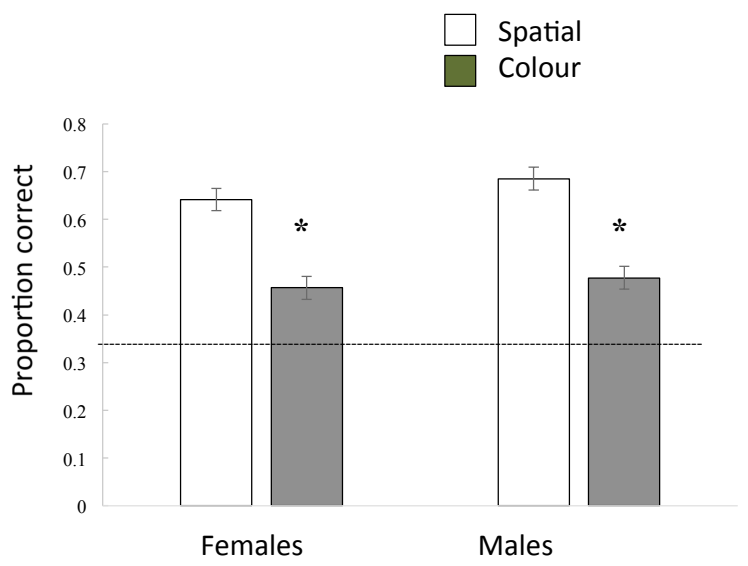

Figure 4 Female and male brown-headed cowbirds both performed better on the spatial than the color touchscreen task. All birds performed above chance (horizontal line) on both tasks. Asterisks indicate a significant difference, $P<0.05$ non-breeding males. Male performance also grew poorer with increasing RI whereas female performance did not.

It is possible there are trade-offs between kinds of spatial ability (Sherry \& Schacter 1987). For females, dedicating cognitive and neural resources to navigation and memory for real world nest-like spatial locations may come at the cost of performance on other tasks that
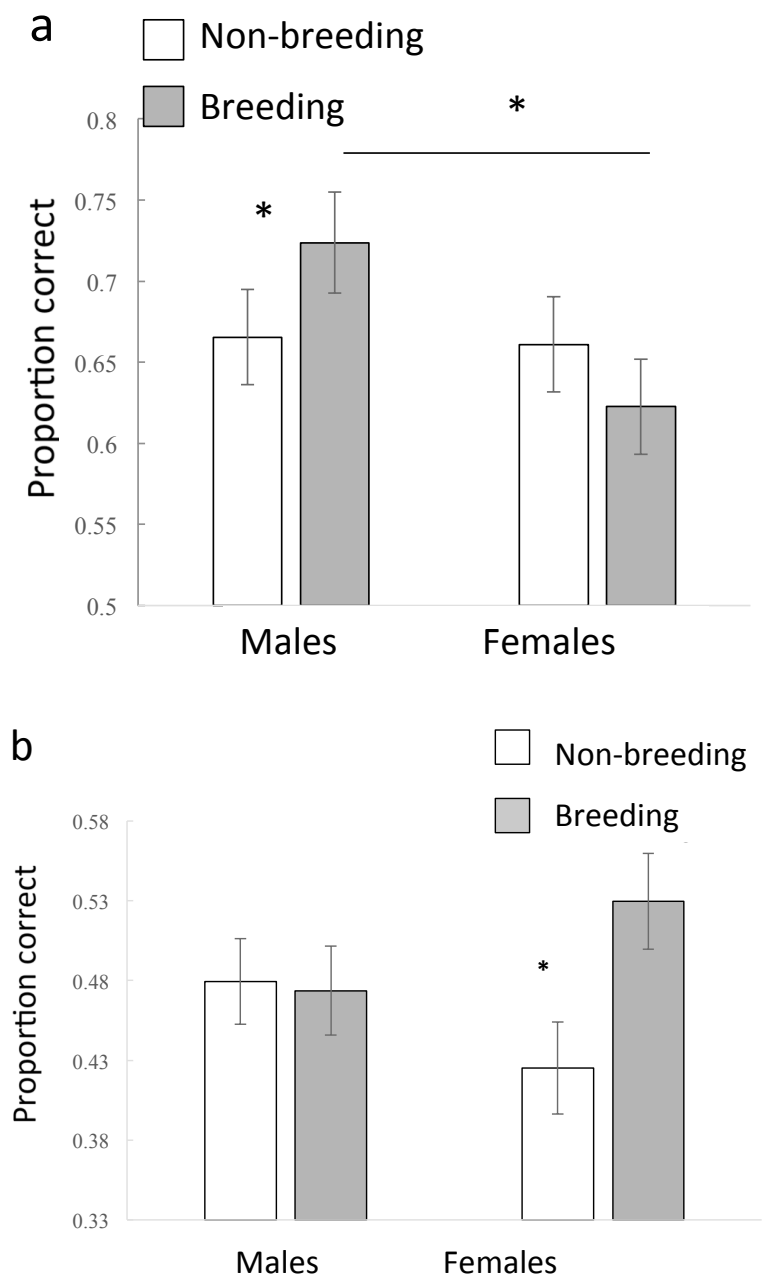

Figure 5 (a) Male brown-headed cowbirds in breeding condition performed better than females in breeding condition and better than males in non-breeding condition on the spatial touchscreen task. (b) Female brown-headed cowbirds in breeding condition performed better than females in non-breeding condition in the color task. There was no overall significant difference between the sexes on the color task. Asterisks indicate a significant difference, $P<0.05$. 
have a spatial component. It is also possible, however, that superior male performance on the spatial touchscreen task reflects specialization for some unknown behavior that requires relatively short-lasting memory for proximal spatial location, and the improvement in performance on the spatial touchscreen task that comes with breeding condition in males but not females suggests that this may be the case.

The improvement that occurs in performance of the touchscreen color task that occurs in females only during breeding condition could, similarly, reflect specialization for a behavior they perform in the wild. Male brown-headed cowbirds have an iridescent black plumage that contrasts with their chocolate brown head, and females may use and remember iridescent color in order to choose among potential mates in a way that males do not. The plumage of nutritionally stressed male brown-headed cowbirds has a different hue and lower brightness and saturation than the plumage of males fed ad libitum (McGraw et al. 2002). It is also possible that female brown-headed cowbirds discriminate among hosts based on host egg color, which could lead to improved short-term memory for color stimuli in females but not males during breeding.

These hypotheses, however, require testing. Further tests of the idea that superior female spatial ability is associated with search for host nests could be performed in large enclosures (e.g. White et al. 2017) that more closely resemble the spatial scale at which females search for host nests. Superior performance by male brown-headed cowbirds in breeding condition on the touchscreen spatial task is puzzling but the domain of this sex difference could be further examined by varying the kind of spatial task presented on the touchscreen, in more naturalistic foraging tasks or in tests of memory for the spatial location of females. Similarly, the domain of superior performance by breeding females on the touchscreen color task could be examined in tests of discrimination by females between potential mates or in tests using host eggs as stimuli.

\section{SEX DIFFERENCES IN THE BRAIN}

\section{Hippocampal size}

Sex differences in cognition are the outcome of sex differences in the brain. Whether sex differences in cognition are the result of sexual development and differentiation or the outcome of differences in individual experience, whether they are inflexible or transient, dif- ferences in cognition between individuals are the outcome of neural differences and sex differences in spatial cognition are likely to involve the hippocampus. The first investigation of possible sex differences in the hippocampus of cowbirds compared the size of the hippocampus, relative to the size of the telencephalon (or forebrain), in male and female brown-headed cowbirds and a closely-related non-parasite, the red-winged blackbirds [(Agelaius phoeniceus (Linnaeus, 1766); Sherry et al. 1993]. The results showed that female brown-headed cowbirds had a larger hippocampus, relative to the size of their telencephalon, than male brown-headed cowbirds and that no sex difference occurred in red-winged blackbirds. In addition, brown-headed cowbirds had a larger hippocampus than red-winged blackbirds, despite having a smaller telencephalon than the larger redwinged blackbirds (mean weights: red-winged blackbirds $47.7 \mathrm{~g}$; brown-headed cowbird $39.7 \mathrm{~g}$ ).

The most likely explanation for this sex difference in relative hippocampal size is that selection for spatial ability, and in particular memory for the spatial locations of potential host nests, has acted differentially on female compared to male brown-headed cowbirds. In the absence of such sex-specific selection, no sex difference in hippocampal size occurs in red-winged blackbirds. Brood parasitism is not the only difference between brown-headed cowbirds and red-winged blackbirds; they differ in territoriality, mating system, male aggression, song learning and social development, although both are medium range migrants, have similar diets and feed away from the areas of reproductive activity, which are forests, forest edges and woodlands for brown-headed cowbirds and small nesting territories within colonies for red-winged blackbirds. However, specific ecological selection pressures resulting in a sex difference in hippocampal size are likely to involve spatial behavior (Sherry et al. 1992).

Subsequent research with South American cowbirds has supported this conclusion. Reboreda et al. (1996) examined the hippocampus of 3 species of cowbirds, the shiny cowbird [Molothrus bonariensis (Gmelin, 1789)], a generalist brood parasite like the brown-headed cowbird, the screaming cowbird (Molothrus rufoaxillaris), a specialist brood parasite that parasitizes primarily the grayish baywing [Agelaioides badius (Vieillot, 1819) formerly known as the bay-winged cowbird Molothrus badius (Vieillot, 1819)], and the non-parasitic grayish baywing. Shiny cowbird females search for host nests unassisted by males, and like brown-headed cowbirds, parasitize several hundred species of host. 
Screaming cowbird females and males search together for nests of the grayish baywing. Grayish baywings are not brood parasites and incubate their own eggs and raise their own young (and when parasitized, the young of screaming cowbirds). The results showed that both brood parasites had a larger hippocampus, relative to the size of the telencephalon, than the non-parasitic grayish baywing. Female shiny cowbirds had a larger hippocampus, relative to the size of the telencephalon, than males but there was no sex difference in relative hippocampal size in either screaming cowbirds or the grayish baywing. As in the case of brown-headed cowbirds, search for host nests by females appears to have selected for greater hippocampal size in females than in males. When no sex difference in spatial behavior occurs, as in red-winged blackbirds, screaming cowbirds and grayish baywings, there is also no sex difference in hippocampal size. It is notable that even though shiny cowbird females search for host nests and males do not, mean relative hippocampal size is larger in shiny cowbirds than in screaming cowbirds and grayish baywings, suggesting that selection acting primarily on females has also acted to increase hippocampal size in males, compared to the other species examined in this study. Selection on one sex can produce phenotypic effects on both sexes because most genes are shared by males and females and, therefore, additional relatively intense sex-specific selection is necessary to produce the kind of sex differences observed in hippocampal size in the generalist brood parasites (Lande 1980; Wyman et al. 2013).

These two examinations of sex differences in the hippocampus (Reboreda et al. 1996; Sherry et al. 1993) looked at birds collected during the breeding season: April to May for brown-headed cowbirds collected in the northern hemisphere in Canada; and December to March for cowbirds collected in the southern hemisphere in Argentina. If greater hippocampal size in females than in males is an adaptation to spatial search and spatial memory involved in finding and remembering potential host nests, then it is possible that it occurs only during breeding and not at other times of year. Sex differences in the hippocampus of rodents show seasonal variation correlated with breeding activity (Galea \& McEwen 1999; Omerod \& Galea 2003; Galea et al. 2013). This seasonal variation probably occurs because brain tissue is expensive. In songbirds, the song control nuclei increase in size during breeding when males are singing to defend territories and attract mates. In food-storing birds like the black-capped chickadee [Poecile atricapillus (Linnaeus, 1766)] the hippocampus changes in size seasonally in a rough correlation with the waxing and waning of food storing behavior (Sherry \& MacDougall-Shackleton 2015). Clayton et al. (1997) examined seasonal change in the hippocampus of the South American cowbirds described above and found that the hippocampus was larger, relative to the size of the telencephalon, in the breeding season than in the non-breeding season in both the generalist shiny cowbird and the specialist screaming cowbird (Clayton et al. 1997). In the shiny cowbird but not the screaming cowbird there was a sex difference in relative hippocampal size in favor of females and there was no interaction between sex and breeding season in relative hippocampal size in shiny cowbirds (Clayton et al. 1997)

More recent research with brown-headed cowbirds adds further detail to this general picture of seasonal change and sex differences in the hippocampus of brood parasites. In a study of brown-headed cowbirds and red-winged blackbirds collected during breeding and post-breeding, Guigueno et al. (2016) found that cowbirds had a larger hippocampus relative to the telencephalon than red-winged blackbirds, females had a greater relative hippocampal size than males in both species, and there was no effect of breeding season on relative hippocampal size. These findings differ from previous results showing a sex difference in relative hippocampal size in generalist but not specialist parasites or non-parasites (Sherry et al. 1993; Reboreda et al. 1996), although one previous study found no sex differences in hippocampal size in any of shiny cowbirds, screaming cowbirds or grayish baywings (Nair-Roberts et al. 2006). Guigueno et al. (2016) also found no indication of seasonal change in the size of the hippocampus in either brown-headed cowbirds or red-winged blackbirds, in contrast to previous findings with the shiny cowbird generalist parasite (Clayton et al., 1997). It is not clear why the results of Guigueno et al. (2016) differ from previous findings. Specifically, Guigueno et al. (2016) found that while a sex difference in favor of females in relative hippocampal size, indeed, occurs in a generalist brood parasite, it also occurs in a non-parasite, and that there appears to be no seasonal change in relative hippocampal size in brown-headed cowbirds. The sample sizes in this study are larger than in previous studies, plumage and skull pneumatization were used to confirm that all birds were adults, and breeding condition was confirmed by androgen assay. The notable result of this study was not that there is no sex difference in hippocampal size in the brood parasite (there was) but that a similar sex difference, also in favor of females, occurred 
in non-parasitic red-winged blackbirds.

\section{Hippocampal neurogenesis}

We quantified hippocampal neurogenesis in brown-headed cowbirds and red-winged blackbirds using doublecortin (DCX) as a marker for migrating and differentiating neurons. Female brown-headed cowbirds exhibited greater hippocampal DCX immunoreactivity than males in the neuroproliferative subventricular zone, and this sex difference did not occur in redwinged blackbirds (Figs 6 and 7; Guigueno et al. 2016). In addition, there was a higher level of subventricular zone neurogenesis in brown-headed cowbirds in the post-breeding period and a difference in the opposite direction between the breeding and non-breeding periods in red-winged blackbirds. These sex and seasonal differences in hippocampal neurogenesis in brown-headed cowbirds may be the outcome of specialization of the hippocampus of female brown-headed cowbirds for locating and remembering potential host nests. Female brown-headed cowbirds show greater subventricu-
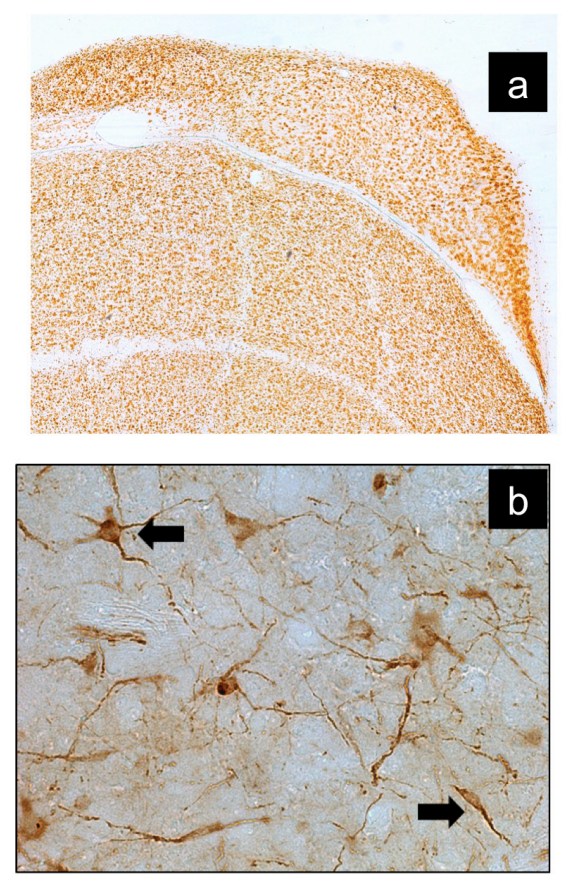

Figure 6 (a) The hippocampus of the brown-headed cowbird labeled with NeuN to show mature neurons. (b) New hippocampal neurons labeled with doublecortin, showing a differentiating neuron (upper black arrow) and a migrating neuron (lower black arrow). lar production of new hippocampal neurons than males and this sex difference is absent in the non-parasitic redwinged blackbird. In addition, there is more production of new neurons in the subventricular zone and migration of more new neurons into the hippocampus in brown-headed cowbirds following breeding than during breeding. In red-winged blackbirds, more new neurons are found in the hippocampus during breeding than following breeding. One hypothesis to explain this seasonal effect in brown-headed cowbirds is that the recruitment of new neurons into the hippocampus following breeding prepares the hippocampus for the subsequent breeding season and subsequent search for new potential host nests, either by replacing hippocampal neurons that have been lost, or acting selectively on mem-
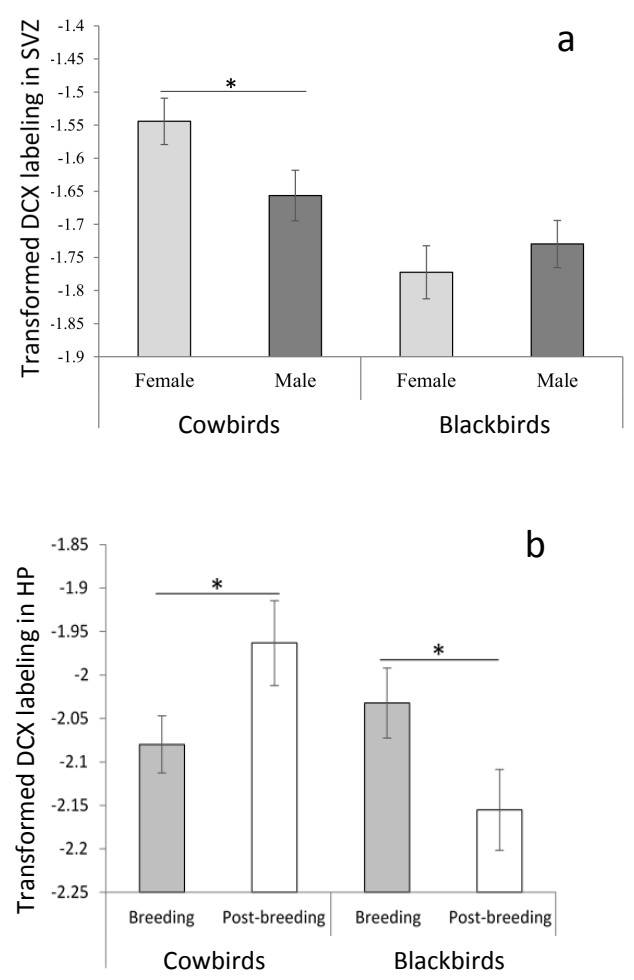

Figure 7 (a) Female brown-headed cowbirds show greater hippocampal neurogenesis, indicated by doublecortin (DCX) immunoreactivity, than males. No sex difference in hippocampal neurogenesis occurs in red-winged blackbirds. (b) Brown-headed cowbirds show greater hippocampal neurogenesis post-breeding than during breeding while red-winged blackbirds show a difference in the opposite direction. SVZ subventricular zone, HP hippocampus. Asterisks indicate a significant difference, $P<0.05$. 
ory. There have been many theoretical proposals and a great deal of experimental work, most of it in laboratory rats and mice, on the function of adult hippocampal neurogenesis (Gould et al. 1999; Lindsey \& Tropepe 2006; Bruel-Jungerman et al. 2007; Kempermann 2008; van Praag 2008; Aimone et al. 2014; Oomen et al. 2014; Cameron \& Glover 2015). One particularly interesting idea in the context of cowbird search for host nests is that hippocampal neurogenesis causes forgetting by disrupting hippocampal circuitry (Frankland et al. 2013). Forgetting has many benefits, from discarding outdated information to reducing proactive interference in memory. Recruitment of new, unbiased neurons into the hippocampus may aid in pattern separation; that is, distinguishing between new memories that share many properties but also have distinguishing features (Frankland et al. 2013). Hippocampal neurogenesis following breeding may remove from memory spatial location and other details of host nests that are no longer suitable for parasitizing and prepare the hippocampal memory system to process large numbers of new nests in the subsequent breeding season, nests that will have many properties in common with each other and with nests of the previous season but also important distinguishing features such as location and the dynamic state of host clutch completion.

\section{CONTEXT-DEPENDENT CELLS IN THE BROWN-HEADED COWBIRD HIPPOCAMPUS}

The relatively large size of the hippocampus and the occurrence of relatively greater levels of adult hippocampal neurogenesis in the brown-headed cowbird suggest that the brown-headed cowbird hippocampus may be specialized for the processing of spatial information. If this is correct, then brown-headed cowbirds may be a promising species in which to look for other neural traits associated with the processing of spatial information. In mammals, there are a variety of cells dedicated to the processing of spatial information. Place cells in the hippocampus, along with grid cells in the entorhinal cortex, and head direction cells in the entorhinal cortex, presubiculum, thalamus and elsewhere in the mammalian brain act together to form an allocentric representation of space (Moser et al. 2008). The avian hippocampus also contains cells that are responsive to a bird's spatial location. In the pigeon hippocampus there are location cells that resemble place cells in some ways (Siegel et al. 2005), path cells (Siegel et al. 2006), and pattern cells that resemble grid cells in some ways (Kahn et al. 2008). If the hippocampus of brown-headed cowbirds, especially female brown-headed cowbirds, is specialized to process spatial information then we would expect, at a minimum, that there are cells in the brown-headed cowbird hippocampus that are sensitive to spatial context.

We tested the sensitivity of brown-headed cowbird hippocampal neurons to spatial context by allowing birds to explore two distinctive spatial environments and then visualizing hippocampal neuron activation using the immediate early gene $\operatorname{Egr} 1$ (also known as ZENK, Zif268, NGFI-A and Krox-24; Grella et al. 2016). Birds were trained to find food in 1 of 5 covered bowls in each of 2 readily discriminable rooms. The rooms differed in the colors of the floor and door; one room had a distinctive depression in the floor that ran from wall to wall, and each room had unique objects on the walls and floor. The location of the baited food bowl differed between rooms. We tested that birds could locate the correct bowl in each room, which they did with $96 \%$ accuracy, to confirm that they discriminated between the rooms. In each room, another bowl was also randomly baited on each trial to encourage exploration and movement and, thus, provide input for hypothesized spatially responsive hippocampal neurons. All birds were trained in both rooms.

On a final testing day birds had two 5-min trials in the rooms separated by $25 \mathrm{~min}$ in their home cages. Some birds experienced the same room twice in succession while others experienced 2 different rooms. Control birds remained in their home cages. Within a few minutes of completion of the second trial, birds were sacrificed for visualization of $E g r 1$ activation in the hippocampus using the method of cellular compartmental analysis of temporal fluorescence in situ hybridization (catFISH). The catFISH method exploits the time course of immediate early gene expression. Hippocampal neurons that were active in the second room only should show Egrl expression in the nucleus only, because sacrifice followed quickly after spatial exploration of the second room. Hippocampal neurons that were active in the first room only should show Egrl expression in the cytoplasm only, because the time between neuronal activity and sacrifice was long enough to allow Egr $1 \mathrm{mRNA}$ to move out of the nucleus into the cytoplasm. If hippocampal neurons were spatially responsive but did not discriminate the 2 spatial contexts of the rooms, most cells would have Egrl in both nucleus and cytoplasm (Fig. 8). However, if hippocampal neu- 
rons discriminated between the 2 spatial contexts, some cells should show cytoplasmic activity only while others showed nuclear activity only. Egr 1 activity in birds that experienced the same room twice in succession would be expected to have both nuclear and cytoplasmic activation because the same hippocampal neurons responded twice in succession to the same spatial context (Grella et al. 2016).

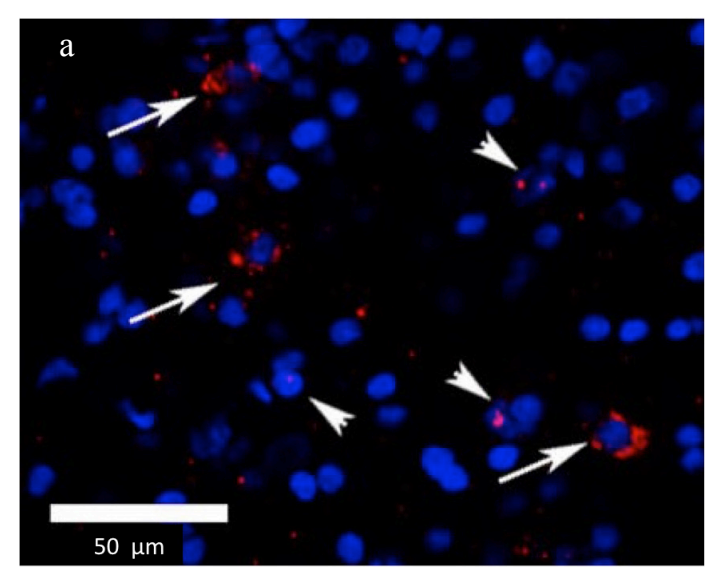

The results showed that some hippocampal neurons were, indeed, active only in the first spatial context (they had $E g r 1$ only in the cytoplasm), others were active only in the second spatial context (they had Egrl only in the nucleus), and some were active in both (Fig. 9). Of the cells that were active in both spatial contexts, significantly more were found in the hippocampus of birds that explored the same room twice in succession com-

Figure 8 (a) Confocal images of brown-headed cowbird hippocampal neuronal nuclei (blue DAPI). Some neurons show Egr 1 mRNA expression (red) in the nucleus (arrowheads), while others show Egr 1 mRNA in the cytoplasm (arrows). (b) Confocal images of hippocampal neurons with Egr1 mRNA expression in both the nucleus and the cytoplasm.
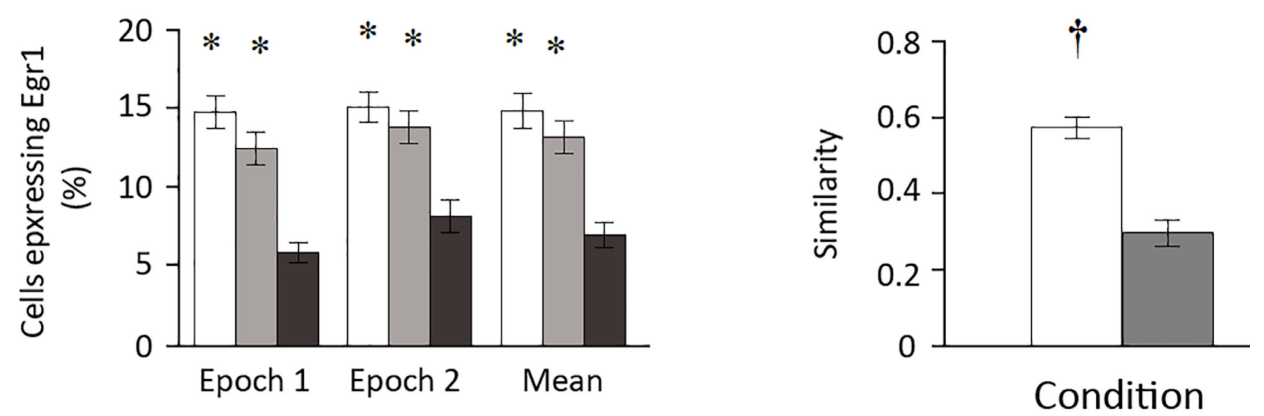

Condition

Figure 9 (a) Percent of hippocampal neurons with Egr1 expression following exposure to 2 spatial contexts. Epochs 1 and 2 refer to the first and second room, respectively. Birds that explored the 2 rooms had significantly more Egr 1 expression than birds that remained in their home cages (black bars) whether they experienced the same room twice (white bars) or 2 different rooms (gray bars). (b) Mean similarity scores show that hippocampal neurons that expressed Egr 1 in response to both the first and second room occurred more often when brown-headed cowbirds experienced the same room twice (white bar) than when they experienced 2 different rooms in succession (gray bars). The similarity score shows how many cells expressing Egr 1 in Epoch 1 also expressed Egr 1 in Epoch 2 and ranges from 0.0 indicating similarity due to chance to 1.0 indicating that all cells expressing Egr 1 in Epoch 1 also expressed $E g r 1$ in Epoch 2. Asterisk and dagger indicate a significant difference, $P<0.05$. 
pared to birds that explored different rooms. These results show that neurons in the brown-headed cowbird hippocampus are, indeed, sensitive to spatial context and that different cells, possibly different networks of cells, respond to different spatial contexts. Place cells in the rat hippocampus show this spatial context dependent pattern of immediate early gene activity (Marrone et al. 2011). This does not prove that the cells we identified in the brown-headed cowbird hippocampus are place cells. Our experiment did not allow us to determine where in the rooms hippocampal neurons expressing $E g r 1$ were active and whether they had the spatial receptive fields that characterize rat hippocampal place cells or pigeon hippocampal location cells. Because the search task was the same in both rooms, with equal reliance on memory for the baited food cup and comparable search among randomly baited food cups, and because the rooms were approximately the same size, it is unlikely the differential activity of hippocampal neurons that we observed was task-dependent. It seems more likely that the differential activity of neurons was the result of differential encoding of two different spatial contexts, but exactly how this occurs, and whether the cells we found correspond to rodent place cells or location, path, pattern or other cells found in the pigeon hippocampus remains to be determined.

\section{CONCLUSIONS}

The reproductive success of brood parasitic female brown-headed cowbirds depends on finding and remembering potential host nests. After finding potential nests, females return to them to monitor host clutch completion, lay an egg, and sometimes remove a host egg. Male brown-headed cowbirds do not search for host nests. The outcome of this sex difference in spatial behavior has been a suite of cognitive and neural adaptations for remembering the location and other properties of host nests. Females perform better than males on spatial tasks that resemble search for host nests but not on another spatial task that does not. Female brown-headed cowbirds possess a larger hippocampus than males, relative to the size of the telencephalon, although recent research shows this is a trait that may be shared with non-parasitic Icterids. Female brown-headed cowbirds do show, however, greater hippocampal neurogenesis than males, a sex difference not found in non-parasitic relatives of brown-headed cowbirds. In addition, hippocampal neurogenesis in brown-headed cowbirds is elevated following breeding, in contrast to the seasonal pattern found in non-parasites. Finally, the hippocampus of brown-headed cowbirds contains spatially responsive hippocampal neurons that may not only be involved in representing the locations and other features of potential host nests but may also be the basis of spatial encoding in the avian hippocampus in general.

\section{ACKNOWLEDGMENTS}

This research was supported by grants from the Natural Sciences and Engineering Research Council of Canada, the Canada Foundation for Innovation, and the Research Development Office of Western University.

\section{USE OF ANIMALS IN RESEARCH}

Original research described in this paper was conducted following the Principles of Laboratory Animal Care (NIH Publication Vol 25 No. 28 revised 1996; http:/grants.nih.gov/grants/guide/notice-files/not96208.html) and the guidelines of the Canadian Council on Animal Care under Animal Use Protocol 2015-019 approved by the Western University Animal Care Committee.

\section{REFERENCES}

Aimone JB, Li Y, Lee SW, Clemenson GD, Deng W, Gage FH (2014). Regulation and function of adult neurogenesis: From genes to cognition. Physiological Reviews 94, 991-1026.

Astié AA, Kacelnik A, Reboreda JC (1998). Sexual differences in memory in shiny cowbirds. Animal Cognition 1, 77-82.

Astié AA, Scardamaglia RC, Muzio RN, Reboreda JC (2015). Sex differences in retention after a visual or a spatial discrimination learing task in brood parasitic shiny cowbirds. Behavioural Processes 119, 99-104.

Bruel-Jungerman E, Rampon C, Laroche S (2007). Adult hippocampal neurogenesis, synaptic plasticity and memory: Facts and hypotheses. Reviews in the Neurosciences 18, 93-114.

Cameron HA, Glover LR (2015). Adult neurogenesis: Beyond learning and memory. Annual Review of Psychology 66, 53-81.

Clayton NS, Reboreda JC, Kacelnik A (1997). Seasonal changes of hippocampus volume in parasitic cowbirds. Behavioral Processes 41, 237-43.

Davies NB (2000). Cuckoos, Cowbirds and Other Cheats. T \& A D Poyser, London.

Deeming DC, Reynolds SJ, eds. (2016). Nests, eggs, 
and incubation. Oxford University Press, Oxford UK.

Frankland PW, Köhler S, Josselyn SA (2013). Hippocampal neurogenesis and forgetting. Trends in Neurosciences 36, 497-503.

Galea LAM, McEwen BS (1999). Sex and seasonal differences in the rate of cell proliferation in the dentate gyrus of adult wild meadow voles. Neuroscience $\mathbf{8 9}$, 955-64.

Galea LAM, Wainwright SR, Roes MM, Duarte-Guterman P, Chow C, Hamson DK (2013). Sex, hormones and neurogenesis in the hippocampus: hormonal modulation of neurogenesis and potential functional implications. Journal of Neuroendocrinology 25, 1039-61.

Gaulin SJC (1992). Evolution of sex differences in spatial ability. Yearbook of Physical Anthropology 35, 125-51.

Gaulin SJC, FitzGerald RW (1986). Sex differences in spatial ability: an evolutionary hypothesis and test. American Naturalist 127, 74-88.

Gaulin SJC, FitzGerald RW (1989). Sexual selection for spatial-learning ability. Animal Behaviour 37, 322-31.

Gould E, Tanapat P, Hastings NB, Shors TJ (1999). Neurogenesis in adulthood: A possible role in learning. Trends in Cognitive Sciences 3, 186-92.

Grella SL, Guigueno MF, White DJ, Sherry DF, Marrone DF (2016). Context-dependent Egrl expression in the avian hippocampus. PLoS ONE 11, e0164333.

Guigueno MF, MacDougall-Shackleton SA, Sherry DF (2015). Sex differences in spatial memory in brown-headed cowbirds: Males outperform females on a touchscreen task. PLOS ONE 10, e0128302.

Guigueno MF, MacDougall-Shackleton SA, Sherry DF (2016). Sex and seasonal differences in hippocampal volume and neurogenesis in brood-parasitic brown-headed cowbirds (Molothrus ater). Developmental Neurobiology 76, 1275-90.

Guigueno MF, Snow DA, MacDougall-Shackleton SA, Sherry DF (2014). Female cowbirds have more accurate spatial memory than males. Biology Letters 10, 20140026.

Hoover JP, Robinson SK (2007). Retaliatory mafia behavior by a parasitic cowbird favors host acceptance of parasitic eggs. Proceeding of the National academy of Sciences, USA 104, 4479-83.

Jacobs LF, Gaulin SJC, Sherry DF, Hoffman GE (1990). Evolution of spatial cognition: sex-specific patterns of spatial behavior predict hippocampal size. PNAS 87, 6349-52.

Jetz W, Sekercioglu CH, Böhning-Gaese K (2008). The worldwide variation in avian clutch size across species and space. PLoS Biology 6, 2650-57.

Kahn MC, Siegel JJ, Jechura TJ, Bingman VP (2008). Response properties of avian hippocampal formation cells in an environment with unstable goal locations. Behavoiural Brain Research 191, 153-63.

Kempermann G (2008). The neurogenic reserve hypothesis: What is adult hippocampal neurogenesis good for? Trends in Neurosciences 31, 163-9.

Lack D (1972). Ecological Adaptations for Breeding in Bbirds. Chapman \& Hall, London UK.

Lande R (1980). Sexual dimorphism, sexual selection, and adaptation in polygenic characters. Evolution 34, 292-305.

Lindsey BW, Tropepe V (2006). A comparative framework for understanding the biological principles of adult neurogenesis. Progress in Neurobiology 80, 281-307.

Louder MIM, Schelsky WM, Albores AN, Hoover JP (2015). A generalist brood parasite modifies use of a host in response to reproductive success. Proceedings of the Royal Society B Biological Sciences 282, 20151615.

Marrone DF, Adams AA, Satvat E (2011). Increased pattern separation in the aged fascia dentata. Neurobiology of Aging 32, e23-32.

McGraw KJ, Mackillop EA, Dale J, Hauber ME (2002). Different colors reveal different information: how nutritional stress affects the expression of melanin- and structurally based ornamental plumage. Journal of Experimental Biology 205, 3747-55.

Moser EI, Kropff E, Moser M-B (2008). Pace cells, grid cells, and the brain's spatial representation system. Annual Review of Neuroscience 31, 69-89.

Nair-Roberts RG, Erichsen JT, Reboreda JC, Kacelnick A (2006). Distribution of substance P reveals a novel subdivision in the hippocampus of parasitic South American cowbirds. Journal of Comparative Neurology 496, 610-26.

Neudorf DL, Sealy SG (1994). Sunrise nest attentiveness in cowbird hosts. Condor 96, 162-9.

Norman RF, Robertson RJ (1975). Nest-searching behavior in the brown-headed cowbird. Auk 92, 610-1.

Omerod BK, Galea LAM (2003). Reproductive status influences the survival of new cells in the dentate gy- 
rus of adult male meadow voles Neuroscience Letters 346, 25-8.

Oomen CA, Bekinschtein P, Kent BA, Saksida LM, Bussey TJ (2014). Adult hippocampal neurogenesis and its role in cognition. WIREs Cognitive Science 5, 573-87.

Reboreda JC, Clayton NS, Kacelnik A (1996). Species and sex differences in hippocampus size in parasitic and non-parasitic cowbirds. Neuroreport 7, 505-8.

Rothstein SI, Yokel DA, Fleischer RC (1987). Social dominance, mating and spacing systems, female fecundity, and vocal dialects in captive and free-ranging brown-headed cowbirds. In: Johnston RF, ed. Current Ornithology. Plenum, New York, pp. 12785.

Scardamaglia RC, Fiorini VD, Kacelnik A, Reboreda JC (2017). Planning host exploitation through prospecting visits by parasitic cowbirds. Behavioural Ecology and Sociobiology 71, 23.

Scott DM (1991). The time of day of egg laying by the brown-headed cowbird and other icterines. Canadian Journal of Zoology 69, 2093-9.

Scott DM, Ankney CD (1980). Fecundity of the brown-headed cowbird in southern Ontario. Auk 97, 677-83.

Scott DM, Ankney CD (1983). The laying cycle of brown-headed cowbirds: Passerine chickens? Auk 100, 583-92.

Sealy SG (1992). Removal of yellow warbler eggs in association with cowbird parasitism. Condor 94, 4054.

Sealy SG (1995). Burial of cowbird eggs by parasitized yellow warblers: An empirical and experimental study. Animal Behaviour 49, 877-89.

Sherry DF, Forbes MRL, Khurgel M, Ivy GO (1993). Females have a larger hippocampus than males in the brood-parasitic brown-headed cowbird. Proceedings of the National Academy of Sciences USA 90, 7839-43.

Sherry DF, Jacobs LF, Gaulin SJC (1992). Spatial memory and adaptive specialization of the hippocampus. Trends in Neurosciences 15, 298-303.

Sherry DF, MacDougall-Shackleton SA (2015). Seasonal change in the avian hippocampus. Frontiers in
Neuroendocrinology 37, 158-67.

Sherry DF, Schacter DL (1987). The evolution of multiple memory systems. Psychological Review 94, 43954.

Siegel JJ, Nitz D, Bingman VP (2005). Spatial-specificity of single-units in the hippocampal formation of freely moving homing pigeons. Hippocampus $\mathbf{1 5}$, $26-40$.

Siegel JJ, Nitz D, Bingman VP (2006). Lateralized functional components of spatial cognition in the avian hippocampal formation: Evidence from single-unit recordings in freely moving homing pigeons. Hippocampus 16, 125-40.

Spritzer MD, Solomon NG, Meikle DB (2005). Influence of scramble competition for mates upon the spatial ability of male meadow voles. Animal Behaviour 69, 375-86.

van Praag H (2008). Neurogenesis and exercise: Past and future directions. Neuromolecular Medicine 10, $128-40$.

White DJ, Ho L, de los Santos G, Godoy I (2007). An experimental test of preferences for nest contents in an obligate brood parasite, Molothrus ater. Behavioural Ecology 18, 922-8.

White DJ, Ho L, Freed-Brown G (2009). Counting chicks before they hatch: female cowbirds can time readiness of a host nest for parasitism. Psychological Science 20, 1140-5.

White DJ, Davies HB, Agyapong S, Seegmiller N (2017). Nest prospecting brown-headed cowbirds 'parasitize' social information when the value of personal information is lacking. Proceedings of the Royal Society B 284, 20171083.

Williams TD (2012). Physiological Adaptations for Breeding in Birds. Princeton University Press, Princeton NJ.

Woolfenden BE, Gibbs HL, Sealy SG, McMaster DG (2003). Host use and fecundity of individual female brown-headed cowbirds. Animal Behaviour 66, 95106.

Wyman MJ, Stinchcombe JR, Rowe L (2013). A multivariate view of the evolution of sexual dimorphism. Journal of Evolutionary Biology 26, 2070-80.

\section{Cite this article as:}

Sherry DF, Guigueno MF (2019). Cognition and the brain of brood parasitic cowbirds. Integrative Zoology $\mathbf{1 4}$, $145-57$. 